Brit. J. vener. Dis. (1964), 40, 191.

\title{
DIAGNOSIS AND TREATMENT OF TRICHOMONAL URETHRITIS IN NIGERIAN MALES*
}

\author{
BY \\ E. NNOCHIRI \\ Department of Medical Parasitology, University of Lagos Medical School, Lagos, Nigeria
}

The observations on which this paper is based were prompted by the high incidence of urethritis in adult males seen at the Yaba Clinic which is the General Out-patient Department of Lagos Teaching Hospital. It was noticed that some of these patients consistently failed to respond to penicillin injections and other antibiotics routinely used here for the treatment of gonorrhoea. Several of them admitted to having received as many as fifty to a hundred injections of penicillin in the Lagos area with practically no improvement in their condition.

The large quantity of expensive drugs wasted on these men is a drain on the economy of these hospitals, thus emphasizing the importance of investigating each patient carefully before instituting treatment.

\section{Material and Methods}

The 100 patients investigated in this study attended the Yaba Clinic from August to December, 1963, and the material examined was obtained from one or more of the following sources:
(1) Urethral discharge.
(2) Urethral scrape.
(3) Centrifuged urine.

A detailed history was obtained from each patient and a thorough physical examination made. Smears of urethral secretions were stained with Gram stain and examined microscopically under the $\frac{1}{12}$ " objective. Where there was no obvious secretion, urethral specimens for microscopical examination were taken by the method advocated by Lanceley (1954) by gently stroking the urethral wall with a platinum loop. Cultures for $T$. vaginalis, using the liquid liver medium of Feinberg and Whittington (1957), were performed in all non-gonococcal cases, and centrifuged deposits of their urine were examined microscopically and put up in cultures.

\footnotetext{
* Received for publication December 10, 1963.
}

\section{Results}

Trichomonas vaginalis was found in eight cases (8 per cent.). A diagnosis of gonococcal urethritis was confirmed in 66 patients from whose urethral discharge Gram-negative "coffee-bean"-shaped intra- and extra-cellular diplococci were isolated. The remaining 26 patients were grouped together as cases of non-gonococcal urethritis for further investigation. The ages and diagnoses of these patients are shown in the Table.

TABLE

AGE AND DIAGNOSIS OF 100 NIGERIAN MALES WITH URETHRITIS

\begin{tabular}{c|c|c|c}
\hline \multirow{2}{*}{$\begin{array}{c}\text { Age Group } \\
\text { (yrs) }\end{array}$} & \multicolumn{2}{|c|}{ Number of Cases Treated } \\
\cline { 2 - 4 } & $\begin{array}{c}(a) \\
\text { Gonorrhoea }\end{array}$ & $\begin{array}{c}(b) \\
\text { T. vaginalis }\end{array}$ & $\begin{array}{c}\text { (c) Non- } \\
\text { gonococcal } \\
\text { (non-specific) } \\
\text { Urethritis }\end{array}$ \\
\hline $10-15$ & 4 & 0 & 0 \\
$16-20$ & 22 & 0 & 8 \\
$21-30$ & 30 & 2 & 7 \\
$31-40$ & 7 & 4 & 10 \\
$41-50$ & 3 & 2 & 1 \\
\hline All Ages & 66 & 8 & 26 \\
\hline
\end{tabular}

\section{Illustrative Cases}

The three following case histories are given in detail to illustrate the type of history obtained from patients presenting with trichomonal urethritis.

Case 1, a technician from the Posts and Telegraphs Workshop at Lagos, was seen at the Yaba Clinic on October 28, 1963, with a history of pain on micturition and urethral discharge of 4 weeks' duration. He admitted extramarital sexual exposure 3 days before the onset of symptoms, having been separated from his wife for the past 18 months.

Before reporting at the Clinic, he had had over 85 injections of penicillin at several other hospitals in the Lagos area and had taken 36 capsules of tetracycline and 
several ounces of mist. pot. cit. with no improvement. Nor had infusions obtained from traditional herbalists helped him. He described an itchy sensation down the shaft of the penis posteriorly. He had been taking codeine tablets for "internal fever" and frequently experienced pain across the back and down both lower limbs. His past history included a previous "gonococcal" urethral infection in 1961 which had cleared up completely with injections of penicillin. His concentration at work was becoming noticeably impaired and he was in danger of losing his job.

Examination.-He looked worried and anxious. Apart from a profuse white frothy discharge at the external urethral meatus, no abnormal physical signs were found. $T$. vaginalis was recovered from the urethral discharge and from a liquid liver medium of Feinberg and Whittington (1957) 3 days after it was inoculated with the urethral discharge.

Treatment.-He was given metronidazole (Flagyl) orally $300 \mathrm{mg}$. twice daily doses for 7 days. When he was seen at the follow-up clinic 4 days later, he had no pain on micturition, the urethral discharge had become considerably less, and he looked a much happier man. A wet film preparation of the urethral discharge was negative, but $T$. vaginalis was recovered from the culture medium inoculated with the urethral discharge at this visit. Treatment was repeated with metronidazole for a further week and tests of cure, including wet film and culture taken one week after the second course of metronidazole, were negative. He was instructed to report at monthly intervals for re-examination but he defaulted, and it is unlikely that he will reappear at the Clinic unless trouble recurs.

Case 2, a laundry attendant aged 36 years, attended the Yaba Clinic on August 24, 1963, complaining of pain on micturition with occasional whitish urethral discharge for the past 5 years. He was married and had two children. There was a past history of gonococcal infection which had been successfully treated with penicillin injections in 1956. He had had all sorts of treatment for his present condition including tablets, injections, and infusions of local herbs with no improvement.

Examination.-There were no abnormal physical findings. Urethral discharge, obtained by gently scraping the urethral wall with a platinum loop, was put up in a Feinberg-Whittington medium. A wet preparation was negative for $\boldsymbol{T}$. vaginalis and a Gram-stained specimen showed diphtheroids and Gram-negative bacilli presumed to be coliform organisms. The urinary sediment contained many epithelial and pus cells. $T$. vaginalis was isolated from the culture medium 3 days after it was inoculated with the urethral discharge.

Treatment.-He was given metronidazole $300 \mathrm{mg}$. thrice daily for 7 days. A wet film and culture taken a month after treatment, were negative and the patient's symptoms had cleared up completely.

Case 3, a school-teacher aged 28 years, was seen at the Yaba Clinic on September 16, 1963, complaining of pain on micturition and urethral discharge, both dating from 1961. He denied any history of sexual exposure and thought he had a discharging ulcer in the urethral meatus. He was preparing to get married in December, 1963, and felt something must be done about his condition. He had had treatment in most of the hospitals in the Lagos area consisting of well over 100 penicillin injections, tablets, and herbal infusions with no improvement.

Examination.-The only abnormality was a profuse thick frothy urethral discharge from which Trichomonas vaginalis was readily isolated. The wet film and culture were both positive though no trichomonads were found in the urinary sediment.

Treatment.-He was given metronidazole $300 \mathrm{mg}$. thrice daily for 7 days. As the test of cure was still positive a week after his first course, treatment was repeated for a further 7 days.

When seen at the follow-up clinic a month after treatment, his symptoms had subsided and a wet-film preparation and culture of the material obtained from a urethral scrape were negative for $T$. vaginalis.

\section{Discussion}

Marchand (1894) was the first to isolate Trichomonas vaginalis in the genital tracts of male patients. The many other instances and series of cases published since that time are due, in part, to improved techniques and the increasing interest in nongonococcal urethritis in recent years. The reported incidence has varied greatly in different hands. Ackermann (1935) failed to find $T$. vaginalis in the urethral secretions of 37 men with non-gonococcal urethritis, though the parasite was present in the vaginal secretions of six of their consorts. Allison (1943) found $T$. vaginalis in 15 per cent. of a group of white patients with gonorrhoea or other genital infections and in 200 Negroes who had been rejected for military service because of venereal disease. Feo (1944) found the parasite in 121 of 735 male negroes (16.4 per cent.) and in 23 of 191 male white patients (12 per cent.). The highest recorded incidence is reported by Coutts, Vargas-Salazar, SilvaInzunza, Olmedo, Turteltaub, and Saavedra (1955), who claimed that 68 per cent. of 2,482 male patients in Chile were infected with this parasite.

That the culturing of urethral smears improves the chances of finding the parasite was convincingly demonstrated by Whittington (1957) who cultured the seminal fluid of 26 men whose wives were or had recently been infected with $T$. vaginalis. The organisms were found in seven of the 26 specimens; six of these were positive culturally, but only in two of the specimens could flagellates be observed microscopically. In a series reported by Catterall (1960), cultures were performed in 63 cases and were 
positive in 58 (92 per cent.), while direct microscopy on 126 known cases gave positive results in 112 ( 88.8 per cent.).

The absence of urethral discharge in some of the present series of patients (e.g. Case 2), must be stressed in order to emphasize that a gentle urethral scrape, preferably with a platinum loop, is an important diagnostic procedure in investigating trichomonal urethritis in males. Catterall (1960) found no evidence of urethral discharge, even on early morning testing, in $6 \cdot 3$ per cent. of his 126 cases, nor was urethral discharge seen at the first examination in $30 \cdot 1$ per cent. of these men.

Trichomonal urethritis was found more commonly among the older age groups in the present series (Table). All eight patients had had symptoms for from 2 to 5 years, during which time they had been treated with many injections, tablets, and herbal infusions.

Metronidazole (Flagyl) is now known to be very effective in the treatment of trichomonal urethritis. It destroys the parasite in the great majority of cases in one course of treatment lasting for 7 days, which may be repeated in chronic cases. No toxic effects followed the use of this drug in the present series.

\section{Summary}

Of 100 Nigerian male adults complaining of urethritis, eight were found to be harbouring Trichomonas vaginalis in the genital tract, 66 had gonorrhoea, and 26 others were classified as cases of non-gonococcal urethritis. Trichomonal urethritis must be excluded in all adult males giving a history of urethritis of over 2 years' duration, particularly where there has been little or no response to treatment with injections of penicillin. Culturing urethral discharge or scrape in the liquid-liver medium of Feinberg and Whittington (1957) increased the chances of finding $T$. vaginalis. Metronidazole (Flagyl), in doses of $300 \mathrm{mg}$. thrice daily for 7 days, proved effective in treating this infestation, and treatment was repeated in three patients who did not respond to the first course with satisfactory results.

\section{REFERENCES}

Ackermann, A. (1935). Derm. Z., 71, 132.

Allison, G. G. (1943). Sth. med.J. (Bgham, Ala.), 36, 821. Catterall, R. D. (1960). Brit. med. J., 2, 113.

Coutts, W. E., Vargas-Salazar, R., Silva-Inzunza, E., Olmedo, R., Turteltaub, R., and Saavedra, J. (1955). Ibid., 2, 885.

Feinberg, J. G., and Whittington, M. J. (1957). J. clin. Path., 10, 327.

Feo, L. G. (1944). Amer. J. trop. Med., 24, 195.

Lanceley, F. (1954). Brit. J. vener. Dis., 30, 163.

Marchand, F. (1894). Zbl. Bakt., 15, 709.

Whittington, M. J. (1957). Brit. J. vener. Dis., 33, 80.

Le diagnostic et le traitement de l'urétrite trichomonale chez l'homme en Nigérie

\section{RÉSUMÉ}

On étudia 100 cas d'urétrite chez l'homme; la voie génitale fut infestée par $T$. vaginalis dans 8 cas, 66 furent atteints de gonorrhée, et les 26 autres d'urétrite nongonococcique.

Il faut donc déceler les trichomonas chez tous les adultes mâles qui ont souffert d'urétrite pendant 2 ans ou plus, surtout si la pénicilline est inefficace. La culture des suppurations et des frottis urétraux dans le bouillon de culture de Feinberg et Whittington (1957) permit d'identifier $T$. vaginalis. La métronidazole (Flagyl) $300 \mathrm{mg}$. trois fois par jour pendant 7 jours fut efficace contre cette infestation; chez trois malades qui ne furent pas guéris par le premier cours de traitement un deuxième cours réussit. 